\title{
Schamroth sign
}

\author{
Naoki Matsuura MD
}

Cite as: CMAJ 2019 November 11;191:E1251. doi: 10.1503/cmaj.190515

A

71-year-old man presented to our outpatient internal medicine clinic with a 1-month history of digital deformities and 2-week history of dyspnea on exertion. He had no remarkable medical history and was an active smoker with a 30-pack-year history of tobacco smoking. His oxygen saturation was $98 \%$ at room air, and his physical examination showed digital clubbing - specifically, the Schamroth sign (Figure 1A), with obliteration of the diamond-shaped window normally produced between the proximal tips of the nails when the distal phalanges are opposed. A computed tomography scan of the patient's chest showed a solitary mass in the right lower lobe. Further investigations confirmed the diagnosis of lung adenocarcinoma, and a right lower lung lobectomy. Two years after the diagnosis, he is still undergoing chemotherapy, and physical examination showed regression of the Schamroth sign (Figure 1B).

Acquired digital clubbing has been associated with several underlying conditions such as neoplastic, suppurative intrathoracic and diffuse pulmonary and cardiovascular diseases. ${ }^{1}$ Because chronic obstructive pulmonary disease (COPD) itself rarely causes clubbing, ${ }^{1}$ physicians should suspect underlying lung cancer when clubbing is observed in a patient with COPD. ${ }^{2}$ No substantial difference in the prevalence of clubbing has been reported between histologic types of lung cancer. ${ }^{3}$ Regression of clubbing has been reported after treatment, ${ }^{4}$ but the pathophysiologic explanation is unknown.

Although quantitative indicators such as nail-fold angles and phalangeal depth ratio are adequate to confirm digital clubbing, ${ }^{1}$ measuring instruments are required to evaluate these factors. We could identify no prospective validity studies, but Schamroth sign is a reasonable technique for identifying clubbing compared with phalangeal depth ratio, without the use of instrumentation. ${ }^{5}$

\section{References}

1. Myers KA, Farquhar DR. The rational clinical examination. Does this patient have clubbing? JAMA 2001;286:341-7.

2. Sarkar M, Mahesh DM, Madabhavi I. Digital clubbing. Lung India 2012;29:354-62.

3. Baughman RP, Gunther KL, Buchsbaum JA, et al. Prevalence of digital clubbing in bronchogenic carcinoma by a new digital index. Clin Exp Rheumatol 1998; 16:21-6.

4. Callemeyn J, Van Haecke P, Peetermans WE, et al. Clubbing and hypertrophic osteoarthropathy: insights in diagnosis, pathophysiology, and clinical significance. Acta Clin Belg 2016;71:123-30.

5. Pallarés-Sanmartín A, Leiro-Fernández V, Cebreiro TL, et al. Validity and reliability of the Schamroth sign for the diagnosis of clubbing. JAMA 2010;304:159-61.
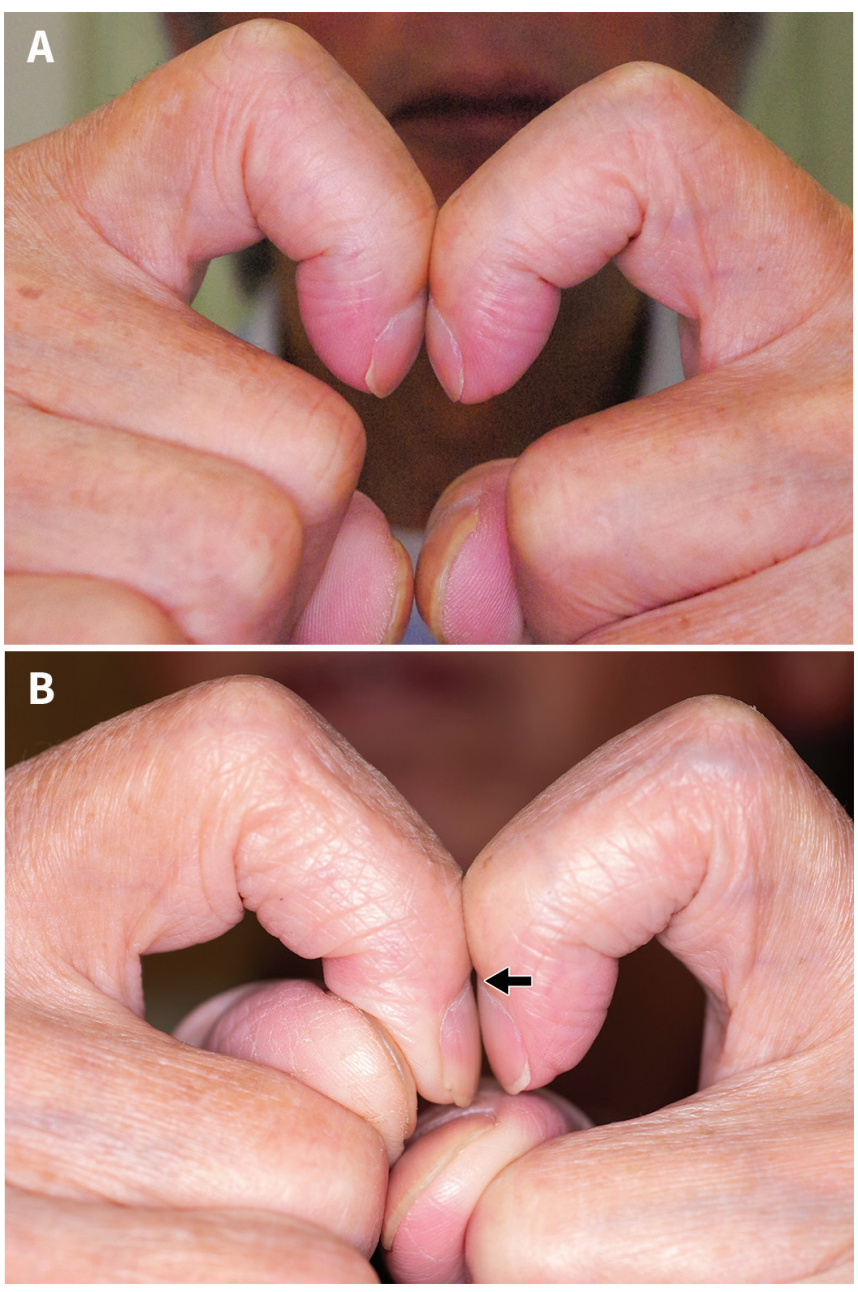

Figure 1: (A) Clinical photograph of the Schamroth sign of a 71-year-old man with lung cancer. (B) Two years after treatment, we observed regression of the Schamroth sign; ie., recovery of the diamond-shaped window (arrow).

\section{Competing interests: None declared.}

This article has been peer reviewed.

The author has obtained patient consent.

Affiliation: Department of Internal Medicine, Koga General Hospital, Miyazaki, Japan

Correspondence to: Naoki Matsuura, naoki.matsura@gmail.com 